\title{
Demineralisation Resistance by Bonding Agent Containing Calcium Oxide-Nanoparticles
}

\author{
Suhad Jabbar Hamed Al-Nasrawi ${ }^{1}$, Wijdan Abdulameer Kadhim ${ }^{2}$, \\ Bushra Habeeb Al-Maula ${ }^{3}$, Abtesam Imhemed Aljdaimi ${ }^{4}$ \\ ${ }^{1}$ Assistance Professor, Department of Conservative Dentistry, University of Kufa, Iraq, ${ }^{2}$ Assistant Lecturer, \\ Department of Conservative Dentistry, University of Karbala, Iraq, ${ }^{3}$ Assistance Professor, Research Center for \\ Laser and Photonics, ${ }^{4}$ Assistance Professor, College of Dentistry and Oral Surgery, Asmarya University, Libya
}

\begin{abstract}
Aim: This study aimed to quantify the effectiveness of bonded Calcium oxide $(\mathrm{CaO})$-nanoparticles as a demineralisation inhibitor.

Methodology: Twelve specimens of enamel were subjected to demineraisation-remineralisation cycles following the application of a bonding agent with or without $\mathrm{CaO}$-nanoparticles. $\mathrm{Calcium}(\mathrm{Ca})$, and phosphorus (P) contents were evaluated utilising energy-dispersive X-ray spectroscopy (EDS). An independent sample t-test was performed to examine the statistical difference between $\mathrm{CaO}$ group and control one.
\end{abstract}

Results: The $\mathrm{CaO}$ group showed higher $\mathrm{Ca} w \mathrm{wt} \%(67.59 \pm 1.68)$ than the control group $(65.22 \pm 0.47)$ with significant difference $(p=0.017)$.

Conclusion: Application of bonding agent containing CaO-nanoparticles could enhance the enamel resistance against cariogenic challenge.

Keywords: Enamel, CaO-nanoparticles, bonding agent, recalcification.

\section{Introduction}

Enamel is the most mineralised and hardest tissue of the human body. Its hardness is mainly attributed to its composition. It is composed essentially of inorganic materials; approximately $95-98 \%$ of it is $\mathrm{Ca}$ and phosphate $\left(\mathrm{PO}_{4}{ }^{3-}\right)$ ions that form hydroxyapatite crystals. Organic materials are roughly made up 1-2\% of enamel composition, containing enamel-specific protein named enamelin, which possesses a pronounced affinity for hydroxyapatite crystals binding. The

\section{Corresponding Author:}

\section{Suhad Jabbar Hamed Al-Nasrawi}

Assistant Professor, Department of Conservative

Dentistry, University of Kufa, Iraq

e-mail: suhad.alnasrawi@uokufa.edu.iq reminder composition of enamel is made up of water, which accounts for about 4\%. Enamel constituents are highly organised; millions of hydroxyapatite crystals are organised in thin, elongated structures $(4-8 \mu \mathrm{m})$ called rods. The number of rods ranges from 5 million to 12 million. Each rod is surrounded by a sheath made up of protein $^{[1-3]}$. The area between rods (inter-rod enamel) has the crystal of different orientation from that of enamel rods. Small spaces free of crystals exist between rods, called pores. They contribute to the permeability of enamel that allows diffusion and fluid movement to occur, but also varies the density and hardness of tooth, which can produce vulnerable sites which are more susceptible to demineralisation where pores enlarge and crystalline structure shrink in size $\mathrm{e}^{[3,4]}$.

Dental demineralisation and remineralisation are dynamic processes coexisted in a balance throughout life. When the demineralisation outweighs remineralisation, the mineral contents of the dental tissue dissolve, starting 
a dental caries. When the remineralisation outweighs demineralisation, the caries is reversed, and the demineralised tissue is remineralised ${ }^{[5,6]}$. A dental filling has been applied to repair dental caries. Nevertheless, secondary caries frequently developed at the restoration tooth interface. Moreover, tooth restoration might need to be changed due to material deterioration, crack, or fracture. Therefore, it is a significant challenge for preventive and operative dentistry to induce the remineralisation of hypomineralised caries lesion. The remineralisation of demineralised dental tissue is the process of mineral restoration ${ }^{[7]}$. Remineralising agents are available in many forms, such as fissure sealants, restorative materials, mouth rinses, chewing gums, and dentifrices $^{[8,9]}$.

With the invasion of nanotechnology, some researchershaveexamined theapplicationofnanoparticles in preventive and restorative dentistry. Recently, the application of nanotechnology in the science of dentistry has grabbed significant attention. Nanoparticles are materials with particles size ranging between 1 and $100 \mathrm{~nm}$, possessing special physicochemical features and a wide range of uses encompassing pharmaceutical applications. The nanoparticles-based formulation for localised delivery in the oral cavity can be existing as aqueous suspensions, or it could be incorporated into the constituents of a gel or paste ${ }^{[10-12]}$.

Calcium is the most significant natural constituent of teeth. Thus, many calcium derivatives have been expressed great potentials to be applied in teeth related disorders due to their biocompatibility and biodegradability ${ }^{[13]}$. Calcium, fluoride, and phosphorus ions play a vital role between remineralisation and demineralisation processes and subsequently modify the progression of dental caries ${ }^{[14]}$. Adhesive systems containing calcium compound as calcium chloride or calcium phosphate were previously investigated. Shinkai et al. examine the effect of adding calcium chloride on microtensile bond strength, where an adverse effect was recorded ${ }^{[15]}$. In another study, Shinkai added calcium phosphate to a bonding agent with a non-significant effect for the addition on the result ${ }^{[16]}$.

Calcium oxide is a significant inorganic material with a variety of employments across industrial ${ }^{[17]}$ and dental application ${ }^{[18]}$. To date, no researches have been performed to study the synthetic $\mathrm{CaO}$-nanoparticles as demineralisation inhibitor. Thus, the aim of this study was to investigate the effectiveness of bonding agent containing this nanoparticles preserve the surface mineral content against cariogenic challenge. The null hypothesis was: there would be no statistically significant effect for $\mathrm{CaO}$-nanoparticles on the mineral contents of enamel.

\section{Materials and Method}

Calcium oxide-nanoparticles suspension preparation: Calcium oxide nanoparticles were prepared according to a method described by Al-Shaibani et al. ${ }^{[19]}$. $\mathrm{CaO}$ suspension was prepared by adding $10 \mathrm{ml}$ of distal water to $50 \mathrm{mg}$ of $\mathrm{CaO}$-nanoparticles powder, and it was shacked very well prior to the using. A good mixing was achieved before using for the two suspensions.

Artificial cariogenic solution and saliva preparations: An artificial cariogenic agent of 4.6 $\mathrm{pH}$, and a solution of artificial saliva containing remineralising agents were prepared according to the procedure described by $\mathrm{Ou}$ et al. ${ }^{[20]}$.

Sample preparation: Twelve enamel samples were prepared from anonymised impacted third molars to be used in this study. Ethical approval for this study was performed by the Ethical Committee of University of Kufa (reference number 7 in 05/03/2018) which was obtained according to the ethical standards and Declaration of Helsinki placed in the 1964 and its later amendments. Any specimens with crack, a sign of hypocalcification or defect were discarded.

All the crowns were sectioned coronally at the cemento-enamel junction. Each crown was positioned into moulds with the buccal surface facing down (base) and fixed in place with sticky wax to be mounted in an acrylic resin. After setting, the blocks were removed from the moulds, and each base was ground and polished to create a flat enamel surface. The selected specimens were randomly divided into two groups according to the received treatment:

Control group: The samples were treated with 37\% phosphoric acid and after that were coated by bonding agent (Tetric N-Bond, Ivoclar Vivadent, Switzerland).

CaO group: The samples were treated with $37 \%$ phosphoric acid followed by a coating material composed of a combination of one drop from each of $\mathrm{CaO}$ suspension and Tetric-N bonding agent. 
All the coating materials were cured by light cure device for $10 \mathrm{~s}$, then subjected to demineralisationremineralisation cycles. Each cycle involved sample immersion in the artificial cariogenic solution for $1 \mathrm{~h}$, followed by immersion in the artificial saliva for 11 h. The two solutions were changed daily. Throughout the period, samples were at $37^{\circ} \mathrm{C}$ under $100 \%$ relative humidity.

SEM-EDS examination: Post-treatment mineral contents of the enamel samples were measured as $\mathrm{wt} \%$ of $\mathrm{Ca}$ and $\mathrm{P}$. The samples were dehydrated with a series of ethanol concentrations: $50 \%, 75 \%, 90 \%$ and $100 \%$ respectively, for 20 minutes for each concentration, to remove any remnant of water.

Then, they were coated with $24 \mathrm{~nm}$ gold layer using Sputter Coater (Quorum technologies Ltd, Laughton, East Sussex, England). The elemental analysis was accomplished using SEM-EDS (Inspect S50, Netherland) at $12 \mathrm{kV}$ accelerating voltage, $10.0 \mathrm{~mm}$ working distance and 5000x magnification. Four spectrums were taken for each sample, and then the average of the readings was calculated. During the elemental analysis, the incoming $\mathrm{kV}$ must be at least 2 times higher than any peak of a measured element ${ }^{[21]}$. The accelerating voltage in this study was $12 \mathrm{kV}$, which is larger than the energy of the electron shells of the measured elements.

Statistical analysis: Mean and standard deviations were calculated, and the data were checked for normal distribution by Shapiro-Wilks test. The effect of mineralising agents on the chemical composition of enamel $(\mathrm{Ca} \%$, and $\mathrm{P} \%)$ was analysed by Independent Sample t-test using SPSS version 22.0 (IBM Corp., Armonk, US) at a confidence level of $95 \%$, and $\mathrm{p} \leq 0.05$.

\section{Results}

The result of the data analysis obtained by EDS for two groups is summarised in Table 1. Mean and standard deviation for the enamel surface elemental analysis of experimental groups. A significant increase in $\mathrm{Ca}$ contents of $\mathrm{CaO}$ group compared to the control group was reported $(\mathrm{P}$-value $=0.017$ ). For $\mathrm{CaO}$ group, the relative content of $\mathrm{P}$ was lower than the control group. However, the difference was statistically non-significant $(\mathrm{P}$-value $=0.129)$.
Table 1: Surface minerals content (wt\%) of sterilised/stored dentine measured by EDS.

\begin{tabular}{|l|c|c|}
\hline Group & Ca wt\% & P wt\% \\
\hline Control group & $65.22(0.47)$ & $32.39(0.10)$ \\
\hline CaO group & $67.59(1.68)$ & $31.54(1.05)$ \\
\hline P-value & 0.017 & 0.129 \\
\hline
\end{tabular}

The $\mathrm{Ca} w \mathrm{t} \%$ and $\mathrm{P}$ wt $\%$ were presented as mean, standard deviation (SD) and p-value of the independent samples t-test.

\section{Discussion}

This study has quantitatively evaluated the remineralisation potential of $\mathrm{CaO}$-nanoparticles on enamel surface subjected to cariogenic challenge. SEMEDS was utilized to record the structural changes of enamel surface ( $\mathrm{Ca} w \mathrm{t} \%$, and $\mathrm{P} \mathrm{wt} \%$ ). This methodology was similar to that used by previous studies ${ }^{[22,23]}$. In the current experiment, the impacted third molars were used for the aim of standardisation and to avoid the effect of variation in the teeth chemical composition.

Remineralisation is a repair process for noncavitated lesions. For the remineralisation enhancement, the increase of Ca concentration in the oral fluids would seem reasonable. Calcium containing compounds rather than phosphate were widely used as a remineralising agent like calcium silicate ${ }^{[24]}$ and Calcium carbonate ${ }^{[25]}$. In fact, $\mathrm{Ca}$ considered as one of the key minerals for remineralisation process ${ }^{[26]}$.

The present in-vitro study mainly demonstrated a remineralising potential of $\mathrm{CaO}$-nanoparticles. A significant increase in the relative amount of surface $\mathrm{Ca}$ content as a result of the application of $\mathrm{CaO}$ nanoparticles was reported in this study. These results were logical, and the rationale for that is $\mathrm{CaO}$ nanoparticles possess $\mathrm{Ca}$ in its chemical composition. Mixing of $\mathrm{CaO}$ with water resulted in the production of calcium hydroxide ${ }^{[27]}$, which was proved to be an effective remineralising agent ${ }^{[28]}$. It was stated that, in the presence of biological fluid, the calcium hydroxide permitting the development of biological apatite ${ }^{[24]}$. On the other hand, the use of a bonding agent may be an effective method to fill porous spaces in demineralised tissue and enhancing remineralisation by containing $\mathrm{CaO}$-nanoparticles. 
The Ca-rich media would enhance $\mathrm{Ca}$ enamel uptake, rise chance of remineralisation. The increase in $\mathrm{Ca} w \mathrm{t} \%$ in the $\mathrm{CaO}$ group reflect the incorporation of the $\mathrm{Ca}$ and regrowing of the hydroxyapatite crystals. It was reported that during the demineralisation process, the Ca loss preceding that of $\mathrm{P}^{[29]}$. Therefore, using of Carich agent for the demineralisation suppression would be efficient. According to the present result, the applied null hypothesis was rejected.

One of the limitations in the current study is the expected differences in the mineral contents of the samples, which might have referred to differences in original contents. However, the selection of teeth of similar criteria with random allocation of the samples to groups makes sure these differences had a minimal effect.

\section{Conclusion}

Despite the limitations, and depending on the data obtained from the current study, we able to demonstrate that the CaO-nanoparticles could enhance enamel resistance to cariogenic attack.

Acknowledgements: The authors wish to thank Dr. Wasnaa Al-Baghdadi from University of Kufa/Faculty of Dentistry at the department of basic sciences for her help in material preparation.

\section{Conflict of Interest: None}

Funding: Self

Ethical Clearance: Not required

\section{References}

1. Avery JK, Steele PF, Avery N. Oral development and histology. 2002: Thieme New York.

2. Fincham A, Moradian-Oldak J, Simmer J. The structural biology of the developing dental enamel matrix. Journal of structural biology, 1999. 126(3): p. 270-299.

3. Robinson $\mathrm{C}$. The developing enamel matrix: nature and function. European journal of oral sciences, 1998. 106(S1): p. 282-291.

4. Simmer JP, Hu J. Dental enamel formation and its impact on clinical dentistry. Journal of dental education, 2001. 65(9): p. 896-905.

5. Featherstone JD. Dental caries: a dynamic disease process. Australian dental journal, 2008. 53(3): p.
286-291.

6. Bertassoni LE. Biomechanical perspective on the remineralization of dentin. Caries research, 2009. 43(1): p. 70-77.

7. Cao CY. Method for biomimetic remineralization of human dentine: a systematic review. International journal of molecular sciences, 2015. 16(3): p. 46154627.

8. de Mendonça Petta T. Chemical Composition and Microhardness of Human Enamel Treated with Fluoridated Whintening Agents. A Study in Situ. The open dentistry journal, 2017. 11: p. 34.

9. Malekafzali B. Remineralizing Effect of child formula dentifrices on artificial enamel caries using a pH cycling model. Journal of dentistry (Tehran, Iran), 2015. 12(1): p. 11.

10. Hannig M, Hannig C. Nanotechnology and its role in caries therapy. Advances in dental research, 2012. 24(2): p. 53-57.

11. Hannig M, Hannig C. Nanomaterials in preventive dentistry. Nature nanotechnology, 2010. 5(8): p. 565.

12. Allaker R. The use of nanoparticles to control oral biofilm formation. Journal of dental research, 2010. 89(11): p. 1175-1186.

13. Dizaj SM. Calcium carbonate nanoparticles; potential in bone and tooth disorders. Pharmaceutical Sciences, 2015. 20(4): p. 175-182.

14. Hara AT, Zero DT. The caries environment: saliva, pellicle, diet, and hard tissue ultrastructure. Dental Clinics, 2010. 54(3): p. 455-467.

15. Shinkai K. Dentin bond strength of an experimental adhesive system containing calcium chloride, synthetic peptides derived from dentin matrix protein 1 (pA and $\mathrm{pB}$ ), and hydroxyapatite for direct pulp capping and as a bonding agent. Odontology, 2010. 98(2): p. 110-116.

16. Shinkai K. Dentin bond strength of a new adhesive system containing calcium phosphate experimentally developed for direct pulp capping. Dental materials journal, 2009. 28(6): p. 743-749.

17. Li X. The remineralisation of enamel: a review of the literature. Journal of dentistry, 2014. 42: p. S12-S20.

18. Amer A Taqa. "Effect of Nano Calcium Oxide Intra Canal Medicaments on the Sealing Integrity of Root Canal Treated Teeth". EC Dental Science, 
2019. 18: p. 1369-1377.

19. Al-Shaibani SW. Evaluation the effect of $\mathrm{CaO}$ Nanoparticles on the body weight and Lipid factors in male Wister Rats.

20. Ou X. Masking white spots of enamel in caries lesions with a non-invasive infiltration technique in vitro. Genet Mol Res, 2014. 13(3): p. 6912-19.

21. Reichelt R. Science of microscopy. Scanning electron microscopy. New York: Springer. p, 2007: p. 133-272.

22. Hegde MN, Moany A. Remineralization of enamel subsurface lesions with casein phosphopeptideamorphous calcium phosphate: A quantitative energy dispersive X-ray analysis using scanning electron microscopy: An in vitro study. Journal of conservative dentistry: JCD, 2012. 15(1): p. 61.

23. Manoharan V. Comparative evaluation of remineralization potential of casein phosphopeptideamorphous calcium fluoride phosphate and novamin on artificially demineralized human enamel: An In vitro study. Contemporary clinical dentistry, 2018. 9(Suppl 1): p. S58.

24. Tay FR. Calcium phosphate phase transformation produced by the interaction of the Portland cement component of white mineral trioxide aggregate with a phosphate-containing fluid. Journal of endodontics, 2007. 33(11): p. 1347-1351.

25. Kleinberg I, SensiStat A. A new saliva-based composition for simple and effective treatment of dentinal sensitivity pain. Dentistry today, 2002. 21(12): p. 42.

26. Gandolfi MG. Calcium silicate coating derived from Portland cement as treatment for hypersensitive dentine. Journal of Dentistry, 2008. 36(8): p. 565578.

27. Ropp RC. Encyclopedia of the alkaline earth compounds. 2012: Newnes.

28. Naseri M. The effect of calcium hydroxide and nano-calcium hydroxide on microhardness and superficial chemical structure of root canal dentin: an ex vivo study. Journal of endodontics, 2019. 45(9): p. 1148-1154.

29. Cummins D. The development and validation of a new technology, based upon $1.5 \%$ arginine, an insoluble calcium compound and fluoride, for everyday use in the prevention and treatment of dental caries. Journal of dentistry, 2013. 41: p. S1S11. 